\title{
DOCUMENTOS
}

\section{John Cage y la posibilidad de pensar el sonido como acontecimiento. Aproximaciones filosóficas a su obra ${ }^{1}$ \\ John Cage and the Possibility of conceiving Sound as an Event. Philosophical Approaches to his Work}

\author{
por \\ Dr. Gustavo Celedón B. \\ Universidad de Valparaíso, Chile \\ gustavo.celedon@uv.cl
}

En una aproximación filosófica a la obra musical de John Cage, se establecen ciertos motivos para afirmar un pensamiento del sonido como acontecimiento. Se trata de concebir el sonido más allá de cualquier trámite significativo para luego, dialogando con Badiou, Derrida y Lyotard, respectivamente, concluir que puede ser pensado en tanto alteridad, vacío lógico e instancia separada de la imagen. Esto supone una historia distante a la Idea y constituye un enigma que transforma a la escucha en una actividad que, más allá de paradigmas y funciones visuales, puede abrir un nuevo espacio para el pensamiento y la reflexión cotidiana.

Palabras clave: Sonido, Acontecimiento, Multiplicidad, Indiferencia, Azar.

As part of a philosophical approach to John Cage's musical work we establish in this article some reasons to conceive sound as an event beyond any matter of significance. Relying on Badiou, Derrida and Lyotard, respectively, we conclude that sound can be very well considered as otherness, as a logical vacuum and as an instance taken separately from image. A history is assumed far apart from the Idea, which amounts to an enigma that transforms listening into an activity which -beyond any visual paradigm or function-can open into new areas for thinking and daily reflection.

Key words: sound, event, multiplicity, indifference, chance.

\section{MÉTODO}

Diversos motivos pueden despertar un interés filosófico por el sonido. Ya en la primera mitad del siglo pasado el antecedente de las vanguardias, con Luigi Russollo y John Cage entre otros, otorgaba al sonido el estatus de cuestión. No obstante, no es solo por el arte que el sonido ha podido ocupar una plaza inquietante para los devenires del pensamiento,

1 Este artículo se desprende de la investigación doctoral que el autor realizó durante los años 2008-2012 con apoyo de la Beca de Doctorado en Chile, CONICYT. 
bien que en su seno es donde mayormente se ha recreado su pregunta, su experimento y su libertad respecto de las consideraciones habituales que de él se han hecho cargo. Es necesario subrayar que si bien toda una ciencia del sonido, producción tecnológica incluida, adquiere un impulso inédito en la historia por medio del surgimiento de los aparatos de reproducción sonora, muy pronto la experimentación y la inquietud artísticas se acoplarán de manera bastante influyente en su evolución. Los trabajos de compositores como Karlheinz Stockhausen y Iannis Xenakis, a modo de ejemplo, producen resultados tanto en el campo artístico como en el científico. En la actualidad el Institut de Recherche et Coordination Acoustique/Musique (Ircam), en París, puede quizás graficar esta síntesis entre ciencia y arte, a la que progresivamente se suma la teoría. Asimismo, un sinnúmero de instituciones y colectivos independientes a lo largo del planeta promueven el desarrollo de la producción sonora en forma paralela con la informática y la promoción de nuevas tecnologías.

"El vínculo histórico entre vanguardias y estructuras de investigación (laboratorios Bell en los Estados Unidos, estudios de cadenas nacionales de radiodifusión en Europa), del cual el Ircam es a la vez el producto y una nueva forma histórica, constituye en efecto el zócalo sobre el cual se apoyan tanto las músicas como las invenciones alternativas para desembocar hoy día en una inmensa carta mundial en el desarrollo de programas y de nuevas prácticas para la creación musical. Sin las intuiciones musicales de los compositores de la década de 1950, formados a la vez en la escritura serial y en el espíritu de investigación de las músicas electroacústicas, no es posible nada de especialización en el sonido, nada de síntesis sonora, nada de tiempo real en escena ni de práctica moderna de montaje y sampleo" 2 .

Este solo ejemplo basta quizás para fundamentar que un trabajo filosófico sobre el sonido, por mucho que fije los límites de su campo de acción e investigación, no puede limitarse solamente a la estética. Este será nuestro caso. Por lo tanto, aun afirmando por motivos metodológicos que la música es un arte y solo un arte, nuestra aproximación a John Cage, uno de los máximos exponentes de la vanguardia del siglo recién pasado, no es simplemente una preocupación filosófica por la música, sino más bien por algo que en la música acontece.

Se podría decir que el método que adoptamos se fundamenta en el pensamiento del filósofo francés Alain Badiou. Por una parte, está lo que él denomina la Inestética o el procedimiento mediante el cual la filosofía persigue los efectos intrafilosóficos de ciertas obras de arte ${ }^{3}$. Por la otra, está el esfuerzo de la filosofía por capturar las verdades o los acontecimientos producidos por lo que él denomina los procedimientos genéricos, a saber, la política, la ciencia, el amor y el arte ${ }^{4}$. Nos corresponde a nosotros justamente el arte, en tanto nos aproximamos al sonido y la música. Pero esto podría ser cierto solo en la medida en que la filosofía no se encuentre con ella misma ejercitándose de antemano, de manera no oficial, en el procedimiento genérico que ocupa su tiempo, o que, por otro lado, no encontremos ya en el arte, a modo de ejemplo, dosis inseparables de amor, de política o, según mencionábamos anteriormente, de ciencia.

$\mathrm{Al}$ respecto, el caso de John Cage es ejemplar. Uno de sus últimos trabajos es una pieza llamada One ${ }^{11}$ (1992), un film que consiste en los movimientos de una luz que se proyecta sobre una pared blanca a oscuras y cuya composición demanda a la cámara asumir el rol de

\footnotetext{
2 Stiegler 2005: 37-38.

3 Badiou 1998.

4 Badiou 1989.
} 
un instrumento musical. Esto no tiene por función presentar la imagen como un sonido, sino más bien de presentarlos, a ambos, de manera indiferente.

Esta indiferencia se aplica también a sus múltiples actividades: ensayista, artista plástico, pintor, micólogo, cocinero. Todo ello lo ejerce en forma separada, pero sin marcar la distinción entre una acción y otra, al punto en que el cocinero, en el instante mismo en que realiza su labor, deviene músico. John Cage es a veces más radical que Crátilo, al sustituir el indicativo por el silencio y abrir, con ello, una nueva dimensión. Una botella de Coca-Cola, dice, ya no es lo misma botella que era hace un rato; es absolutamente diferente ${ }^{5}$. El paso entre una y otra, esa diferencia que se lleva la mismidad para siempre, no es una diferencia de la cual se pueda dar cuenta. Es ella misma indiferente.

De esta manera, el campo de la estética desborda sus propios y aparentes límites. Con John Cage no se tratará nunca del arte por el arte, del arte confinado al lugar de su práctica y su especialización, sino del arte en relación con la vida, por la vida. La vida es arte, esa es la elección cageana por excelencia y entre ambos, vida y arte, está la imposibilidad de marcar la separación. "Para Cage no se trata de pasar, es decir, de destruir la barrera entre el arte y la vida puesto que, justamente, no hay barrera entre ambos"6.

Ahora bien, una diferencia vinculada a un fondo de indiferencia o de no distinción es un tema que ciertamente se encuentra en cierta filosofía contemporánea, principalmente en el llamado post-estructuralismo. De esta manera, las cuestiones de método logran esclarecerse para nuestros propósitos y pronto podemos establecer una reflexión conjunta entre Cage y ciertos pensadores contemporáneos, en particular Jacques Derrida, Jean-François Lyotard y Badiou. Un texto clave que apoya nuestro procedimiento está escrito por el filósofo y músico francés Daniel Charles, ¿La tentación del Oriente? En este texto se pretende reivindicar la calidad teórica del trabajo de John Cage, al afirmar que un reduccionismo a las sabidurías orientales, que de hecho Cage consultó siempre, no agota la inquietud de su obra, al abrir a la música problemáticas que, según Charles, ubican a Cage dentro del post-estructuralismo:

"Optando a la inversa por el indeterminismo, es decir, por la reabsorción de las dualidades en la unidad de su movimiento, Cage concebía la no dualidad como inserta en principio sobre la 'destrucción de las estructuras' - o la deconstrucción. Desde entonces, los dados están tirados: la puesta en proceso de la música, tal cual se inicia con Music of Changes, marcará, de repente, la entrada en el post-estructuralismo"7.

La elección de estos tres autores se fundamenta en ciertos puntos esenciales. Valga decir que nuestro propósito no consiste en validar o reencontrar sus tesis en la música de John Cage. Por el contrario, pretende hacerlas operar, movidos siempre por el convencimiento de que una obra como la del músico norteamericano posee su propia singularidad pensante, constituye una alteridad para el dominio filosófico y puede incluso, según veremos, ir más allá de las propuestas post-estructuralistas.

\section{JOHN CAGE}

Un encuentro perpetuo, móvil e indescifrable, aquel entre sonidos y silencios -ruidos no excluidos-, se ubica en las profundidades de toda experiencia musical. A diferencia de lo

\footnotetext{
5 Sebestik 1992.

6 Lussac 2004: 146.

7 Charles 2011: en línea.
} 
que el término "relación" nos puede sugerir, el encuentro, bien dice Badiou, se produce en el seno de la incalculabilidad ${ }^{8}$ y no está inscrito en ningún logos. Esta experiencia que nace con -a la vez que se aplica a- su experiencia musical, es también constituyente a las cosas, según una ontología que Cage no duda en desarrollar y poner en práctica, en sus palabras, en sus actos, en sus obras. En este sentido, la música se extiende más allá de su rol habitual hacia un escenario que alterando o sublevando el terreno de sus fundamentos, comúnmente no atendidos, asume un rol activo en el ejercicio de pensar y construir una consideración de las cosas. De alguna manera, remover las posiciones habituales que la música ha otorgado al sonido y a los silencios, no solo causaría una revolución en la música, sino que también obligaría a replantearse un sinnúmero de asuntos y posiciones que cruzan diversos planos. De ahí que "el-arte-como-vida" es el espacio en el que los límites se diluyen constantemente, en donde, existiendo diferencias y separaciones, estas se encuentran en un constante y múltiple movimiento, indiferenciando los elementos, desplazándolos y rehaciéndolos en todo momento. La indicación -Crátilo- parece inverosímil y el paso a la escucha hará de Cage el gran pensador que es. Como Daniel Charles hace ver a la filósofa española Carmen Pardo en una entrevista que ambos sostienen, se trata aquí de otra cosa que los ojos. No se trata de ver, sino más bien de escuchar: "Sin embargo, lo que se anuncia podría responder a una disciplina no-visual, al recogimiento de una escucha"9. Volveremos sobre esto.

Para Cage los sonidos son diferentes, singulares: el asunto es que no contamos con esa diferencia: el silencio. Toda una historia de la música, en la que Beethoven y Schönberg son quizás los puntos más significativos, es a ojos de Cage una historia de las relaciones entre los sonidos y no de los sonidos mismos: la Harmonía ${ }^{10}$. Él mismo ha declarado que el único problema de los sonidos es la música ${ }^{11}$. Sin embargo, siempre vuelve a ella, anclado a la promesa de dedicarle su vida, promesa que tempranamente le hizo a Schönberg. Pero para ello era indispensable asumir y construir un gesto, aparentemente ambiguo: hacer la música fuera de la música. Ello toma progresivamente la forma de un desarme de las estructuras armónicas que constituyen el cuerpo musical. Cage no se conforma con la revolución atonal de su maestro en tanto esta multiplica y extrema las cuestiones relacionales de la música, incentivando el control y los cuidados, y cuya máxima manifestación será el serialismo integral. En otras palabras, el entramado relacional que es la música tradicional aún en su versión serial, es una preocupación por asegurar y fascinarse con encadenamientos, omitiendo una atención al sonido y a lo que esta atención habría de modificar en las cuestiones musicales. Con ello la música se somete a lo visual, excluyendo al sonido en una clara tendencia a considerarlo en tanto materia o elemento con el cual se despliegan los más variados y complejos entramados. Cage quisiera girar la atención al sonido. Envolverse en su presentación y no en su representación.

"Apóyese no sobre las alturas, lo que no lo conducirá más que a desarrollar la harmonía a la manera de Beethoven, sino sobre aquello que es común a sonidos y silencios: el tiempo. Verdad perdida en Occidente desde la Edad Media y redescubierta solo por Satie y Webern; verdad jamás perdida en Oriente... Desde este momento, una vía se abre para la música de hoy día: no se trata solamente de dar cuenta, como lo hace Schönberg, de la crisis de la tonalidad, elaborando una red serial de pretil contra la

8 Badiou 1992: 251-273.

9 Pardo 2006: 61.

10 El término se refiere a la noción griega, que es a la vez la armonía musical como la armonía de la existencia, la razón o el logos, la armonía universal.

11 Cage 2002. 
recurrencia de funciones tonales abolidas. Aquella actitud es puramente negativa, participa de la crisis que ella imagina estar conjurando, no hace sino que multiplicar las 'precauciones' -precaución de octava o de quinta o de séptima de dominante o de arpegio-... No, la vía a tomar no pasa solamente por los sonidos o por sus relaciones: ella pasa por los sonidos y los silencios, pasa por el tiempo. / .../ El tiempo es aquello que configura la vida y la muerte de cada sonido y de cada silencio, inerva los dos a la vez. Forma parte de lo más íntimo del sonido como de lo más íntimo del silencio; de esta manera, no existe 'en sî', surge más bien cada vez"12.

Una tendencia a la ecuación experimentación-indeterminación, con variables cuotas de pragmatismo, creará tempranamente el camino que Cage frecuentará para desmontar las estructuras relacionales. El piano preparado introduce la producción de sonidos inesperados: la posición de clavos, tuercas y tornillos entre las cuerdas del piano hacen aparecer en un tiempo y en una escucha no calculada, sonidos precisamente inesperados, como quantums que saltan indeterminadamente. De esta manera, la obra introduce un aspecto no menor. Más allá de la interpretación y la composición, más allá de la relación entre la partitura que condensaría la idea del compositor y la lectura del intérprete, en una discusión sobre la identificación entre interpretación, idea y partitura, existe también el evento mismo, el acontecimiento que es la ejecución -y la temporalidad de la ejecución-y con ello el advenimiento de la sonoridad como tal: anárquica, sin permiso, sostenida por el azar.

Cage extiende el ámbito de la escucha por todos los campos. No es esta la actividad final, lo que vendría luego del juego que pule y crea un armazón sonoro, sino la actividad fundamental que atraviesa todos los niveles, desde la composición y la interpretación que se ven sorprendidas por el advenimiento amplificado de sonidos alterados que reclaman su esencia anárquica, hasta el auditor, cuya asistencia se ve convocada por la retirada amenazante y la disolución progresiva de la objetividad direccionada a la cual su escucha se había acostumbrado. Pronto la obra quizás más conocida de Cage, 4'33” (1952), compuesta de puros silencios y cuyo nombre indica su duración, anulará a todos los agentes del proceso musical para dejar aparecer los sonidos próximos, la actividad que en todo momento está en acción, sonando, ahí cuando el compositor medita su obra, ahí cuando el intérprete ensaya su ejecución, ahí cuando el espectador se concentra en los devenires de la obra. Apagando todo eso, reduciéndolo al silencio, queda esa actividad al desnudo, en el devenir eterno de su acontecer.

Uno de los supuestos alterados, apreciamos, es la clásica dirección que va del compositor al auditor. Aquí se ensaya un enroque constante que deja al compositor como auditor y a este como compositor. Valga lo mismo para el intérprete. "Lo que pasa es que me transformé en auditor y la música devino en algo para escuchar"13.

La escucha antecede al origen y se fusiona con la aparición de sonidos y silencios, comprometiendo y desarticulando la posición de las subjetividades en juego. La música es cuestionada aquí en la disposición de sus sujetos, disposición que encontramos hoy en día incluso en la llamada ciencia acústica. A modo de ejemplo, el trabajo de Émile Leipp afirma que la música es un mensaje y que este, el mensaje, comienza en el cerebro del compositor, se actualiza en la interpretación y llega finalmente al auditor o receptor que no es otra cosa que el consumidor del trabajo composicional ${ }^{14}$. Tal esquema, semejante a la definición

12 Charles 2002: 287.

13 Cage 1973: 7.

14 Leipp 1971: 6. 
platónica de la $\varphi \omega v \tilde{\eta}-$ Timeo-15 y al esquema aristotélico del circuito del conocimiento - peri hermeneias-, que de hecho Derrida pone en cuestión ya en De la Grammatologie ${ }^{16}$, reproduce toda una historia de la primacía de la idea en la cual el sonido queda reducido a la mera materialidad conductora. La yuxtaposición que indiferencia a estos agentes pone a la escucha como actividad primordial, en la que el compositor se encuentra ya antecedido por el encuentro activo entre la escucha y los sonidos-silencios, sin que estos sean un llamado auroral, una palabra lejana propia a lo que Derrida llama el silencio fenomenológico, ese silencio tautológico que en su callar pretende condensar una palabra sin mediación, un saber sabido, un oído absoluto ${ }^{17}$.

No hay nada, y en esto John Cage es categórico, que se esconda tras el acontecer de sonidos y silencios. La escucha es justamente ese reposo que frena la actividad subjetivante y objetivante para extenderse junto al acontecer de estos sonidos.

\section{DERRIDA}

La composición de John Cage se sustrae a la participación del sujeto. Ni ideas, ni gustos. Para ello procede mediante operaciones por azar (chance operations), procedimientos que pretenden imitar los modos con los cuales opera la naturaleza. Esta imitación responde a la definición del arte que nos da John Cage, tomada principalmente de sus lecturas de Ananda Coomaraswamy. Sustraída a cualquier logos y espontaneidad, la naturaleza se caracteriza por distribuir la aparición de sus elementos a través del azar. De este modo, las composiciones de John Cage le permitirán sustituirse a sí mismo por los más variados y diversos métodos de convocación del azar. El más célebre es la utilización del I Ching, el milenario oráculo chino compuesto de 64 hexagramas que le permitían, tras tirar las monedas, decidir sobre los sonidos, sus posiciones, tiempos y duraciones. El uso y la elección de estos métodos son variados, incursionando también en la asistencia por computadores ${ }^{18}$.

Lo importante es que todos estos métodos tienen por función despejar de toda subjetividad la composición y lograr finalmente la puesta en escena de lo inesperado que activa la escucha. El sujeto no querría escucharse a sí mismo, como si la música y la disposición de los sonidos en una porción de tiempo y espacio fuese el desafío de encontrarse. Esa es la cuestión cageana. Al dejar la composición al azar se deja incursionar lo otro: las relaciones

15 "Supongamos, en general, por un lado, la voz, transmitida por el aire como un golpe a través de las orejas, del cerebro y de la sangre hasta el alma y, por otro, el movimiento comenzado por ella, a partir de la cabeza y que termina en la sede hepática: la audición" (Platón, Timeo, 67a). Corresponde este texto a la traducción publicada por la editorial Gredos, a cargo de María Ángeles Durán y Francisco Lissi. Remarcamos no obstante que, por ejemplo, en las traducciones francesas de Victor Cousin y Luc Brison, $\varphi \omega v \tilde{\eta}$, particularmente en este pasaje, se traduce por sonido (son) y no por voz.

16 "Tal como más o menos se la ha determinado implícitamente, la esencia de la phoné sería inmediatamente cercana a aquello que en el 'pensamiento' como lógos tiene relación con el 'sentido', el producto, lo recibido, lo dicho, lo reunido. Si para Aristóteles, por ejemplo, 'los sonidos emitidos por la voz son los símbolos de los estados del alma y las palabras escritas los símbolos de las palabras emitidas por la voz' (Sobre la Interpretación 1, 16a 3), es que la voz, productora de los primeros símbolos, tiene una relación de proximidad esencial e inmediata con el alma”. Derrida 1967: 21-22.

17 Derrida 1967.

18 “...Cage toma decisiones a través de las operaciones por azar derivadas del I Ching. Tradicionalmente se reciben las respuestas del I Ching tirando monedas para obtener combinaciones que refieren a una de sesenta y cuatro posibles símbolos o hexagramas que contiene el oráculo. En 1969 Cage comienza a usar programas computacionales de simulación del I Ching que facilitaban el procedimiento de traducción de los hexagramas a equivalentes numéricos”. Lewallen 2001: 235. 
entre los sonidos se tornan una ficción y la escucha, aun cuando se subsuma bajo el principio de comprender aquello que suena en conjunto, no habría sino de volver, en todo momento e irrepetidamente, a renunciar a la aprehensión y permitirse escuchar, lo cual constituye, sin duda, un misterio.

Podría objetarse, no obstante, que la resultante de una operación por azar podría descifrarse después. Si los esfuerzos de Cage que someten la composición al azar no pretenden lograr ningún tipo de identidad e identificación en y con la obra, esta podría sin embargo encontrarse posteriormente, una vez que la obra se presente. Dicho de otro modo, la obra podría ser decodificada en el futuro.

$\mathrm{Al}$ respecto, se puede aquí recurrir a ciertas ideas que Derrida elabora con relación a Joyce. No resultará del todo ajeno en la medida en que Cage es admirador de su obra y al menos dos de sus piezas, dedicadas al escritor irlandés, incluyen textos suyos ${ }^{19}$. Si bien contamos con la existencia efectiva de un cuerpo literario cuya firma es la de Joyce, Derrida opone la retirada del autor, movimiento de quien se aleja tras el don ${ }^{20}$. A pesar de una inauguración universal de estudios sobre Joyce, de la elaboración del logiciel-Joyce (del software-Joyce) que vendría a dar cuenta de las conexiones y los vínculos que dicha obra ha puesto en marcha para dar con sus resultados, con la obra encuadernada, la lectura de Joyce, lectura imposible, se retrae o sustrae a su acontecer, a los movimientos entre lenguas y entre saltos de consideración que producen algo más parecido a la fugacidad de una estela que a la suposición de una lógica de encadenamientos complejos capaz de generar una especie de programa para reproducir las conexiones mentales de Joyce. Este software supone un viejo tema: los movimientos cerebrales se corresponden con los movimientos de la obra, creando a la vez al sujeto y al objeto y suponiendo incluso el conocimiento de la obra no escrita, que podría perfectamente reproducirse, como si este programa pudiese seguir escribiendo en nombre de Joyce.

Lo mismo aplicamos aquí a Cage: la apuesta por el azar aspira a que siempre el advenimiento de un sonido sea ajeno a cualquier programación. Esto explica una diferencia fundamental en el uso del azar, a saber, la diferencia entre el random y las operaciones por azar. El random, noción ambigua en todo caso, supone un código que conserva en su núcleo un proceso aleatorio y, por lo tanto, todo aquello que adviene está ya inscrito en la corteza de dicho código. En otras palabras, basta una sola tirada, basta una sola apuesta. $\mathrm{Al}$ contrario, las operaciones por azar renuevan las tiradas una y otra vez, desarticulando a cada instante cualquier código programático que quisiera instalarse en el fondo de la composición.

Para John Cage la aparición de los sonidos externos complementa la ejecución de la obra, formando parte de ella. Él está absolutamente consciente de que una obra no está jamás terminada, atravesando y sobrepasando el concepto de Obra Abierta de Umberto Eco ${ }^{21}$, concepto al cual la noción de random, según la descripción aquí dada, le sería más

19 Roaratorio, an Irish Circus on Finnegans Wake (1979) y Writing for the Second Time through Finnegans Wake (mismo año), que es, en verdad, el registro de la lectura que hace Cage del libro de Joyce, registro que ocupará en Roaratorio.

20 Derrida 1987: 55 y ss.

21 Eco 1992. La Obra Abierta pretende remitir a las obras cuya composición trasciende aparentemente el acto del compositor, dejando toda la conclusión de la obra al acto interpretativo. Eco se concentra en la música. Obras de Berio, Stockhausen y Boulez inician la Obra Abierta. Cage aparece posteriormente, para ser cuestionado e incluso despojado de su condición de compositor y ser señalado como "el más inopinado de los maestros zen" (p. 120). A nuestro juicio, tal despojo señala los límites que Eco da a la apertura. Si bien la conclusión está en manos del intérprete, todas las posibles conclusiones están ya presentes en el campo de posibilidades de la composición. Por el contrario, 
apropiada. "Hasta que muera habrá sonidos. Y continuarán después de mi muerte. No debemos temer por el futuro de la música"22.

La noción de "arribante" y "reviniente" -l'arrivant y le révenant- que Derrida maneja a propósito de los espectros y del otro que llega fuera de todo cálculo, es aquí conveniente para la música de Cage ${ }^{23}$. La obra, en cuanto a la aparición o la presentación de un ensamble de sonidos cuya única propiedad es la de surgir como producto del azar que constituye su llegada, no es más que eso: el recorte de una multiplicidad de acontecimientos que viene a acontecer en el instante de su acontecer y cuya longitud se extiende más allá de la última nota, más allá de los posibles aplausos, de la salida del público, del sonido de la puerta al llegar a casa, de las posibles repeticiones melódicas y espectrales que prosiguen incluso en nuestros sueños. El sonido se extiende -y así la obra- y su extensión no esconde nada por debajo del azar de su aparición. Una tirada de dados, para utilizar la frase de Mallarmé, tiene por consecuencias sucesivas tiradas de dados. En todas las direcciones. Luego, cual silogismo, aquello que la obra es, un ensamble de sonidos, no puede refugiarse en la contemplación de sus conexiones, sino más bien en la escucha de su presente que acontece. El sonido es, en efecto, un acontecimiento, que se manifiesta en su llegada sin cálculo y que solo podrá donar la entrega de su acontecer: sonar. "Arriver" en francés tiene esa doble connotación: llegar y ocurrir: "ocurrir arribando" 24.

\section{ALAIN BADIOU}

El caso de Badiou es particular. En Logiques des Mondes habla del acontecimiento-Schönberg como el último acontecimiento musical, cuya línea militante es el serialismo y en el que no encontramos por ninguna parte el nombre de John Cage ${ }^{25}$. Su texto sobre Wagner desarrolla una reflexión quizás más profunda sobre la música y ciertamente sus postulados, que aquí omitimos, no se aproximan al pensamiento que Cage pone en juego. No obstante, hay dos puntos que nos permiten sustentar la tesis del sonido como acontecimiento:

a) Su noción de multiplicidad inconsistente 26 o del acontecimiento "en bruto". Aquí cada múltiple no está diferenciado del otro, puesto que la implementación de una ley de cuenta -la multiplicidad consistente, la harmonía- no ha contabilizado ningún elemento. Más bien los ha liberado y mantenido en la indiferencia, la cual no implica la unidad, puesto que sí hay separación, es decir, silencios que atraviesan y desplazan continua y discontinuamente los múltiples, los sonidos. De esta manera, se puede pensar que cada pieza de John Cage es la puesta en escena, cada vez, de esta inconsistencia múltiple, de este acontecimiento sustraído a la contabilidad global, a la harmonía.

Cage, quien de hecho se caracterizó por dar instrucciones detalladas a los intérpretes, introduce la indeterminación -y no simplemente la apertura- en la composición misma, la cual deja de ser suya, más allá de toda identificación.

22 Cage 1973: 8.

23 Derrida 1976, 1993. Cristina de Peretti y José Miguel Alarcón traducen así la palabra arrivant en Derrida 2012 para señalar "al que llega", "lo que llega". En cuanto a "reviniente" la palabra francesa revenant significa fantasma, aparecido. Se usa la palabra "reviniente" para subrayar el efecto de vuelta, la condición venidera del espectro.

24 En otro estudio, todavía no publicado, realizamos el análisis que pone en estrecha relación la espectralidad derrideana con la sonoridad de Cage.

25 Badiou 2006: 88-89.

26 Badiou 1988: Meditación uno, p. 31, 39. 
Se objetará que el acontecimiento es la obra, en su integridad o al menos en su multiplicidad, y no los sonidos que la componen. Responderemos que un acontecimiento en su estado de inconsistencia es, dentro del pensamiento de Alain Badiou, el sucederse infinito de sus infinitos elementos, es decir, puros acontecimientos.

"Es una característica del múltiple puro, tal cual se piensa en el marco de una teoría de conjuntos. No hay sino multiplicidades, nada más. [...] La entidad [l'étantité] del ente no supone nada más que su composición inmanente, es decir, que es un múltiple de múltiples. Lo que excluye que haya, propiamente hablando, un ser de la relación. El ser, pensado como tal, de manera puramente genérica, está sustraído a todo vínculo [liaison]"27.

La obra de Cage en tanto multiplicidad inconsistente no tiene otro fin que el de poner ahí, en escena, la actividad de los sonidos. Nada de objetos ni de elementos, sino que solo acontecimientos:

"Un sonido no se ve a sí mismo como un pensamiento, como un deber, como necesitando a otro sonido para su esclarecimiento, como etc. No hay tiempo para ninguna consideración -está ocupado en la performance de sus características-: antes de haberse desvanecido debe haber perfectamente realizado su frecuencia, su intensidad, su duración, su estructura de resonancia [overtone structure], la morfología precisa de esto y de sí mismo.

Urgente, único, desinformado de historia y teoría, más allá de la imaginación, central a una esfera sin superficie, su llegar a ser está libre de obstáculos, energéticamente transmitido. No hay escape para su acción. No existe como parte de una serie de pasos discretos, sino que como una transmisión en todas direcciones desde el centro del campo. Está inextricablemente sincronizado con todo lo otro, sonidos, no sonidos, esto último percibido por otros aparatos que el oído, los que operan de la misma manera.

Un sonido no lleva a cabo [accomplished] nada. Sin ello, la vida no resistiría un instante"28.

Una segunda objeción vendrá desde el lado del sujeto. Para Badiou el acontecimiento será en última instancia la intervención de esta multiplicidad inconsistente que, en la línea de sus consecuencias, constituirá al sujeto. Dicha objeción es válida pero no efectiva en tanto es en este punto donde una noción de acontecimiento parece erigirse directamente desde el trabajo de John Cage. Su firme posición de asubjetividad, procura una intervención de la no intervención que tiende a considerar la acontecimientalidad por todas partes. Las operaciones por azar que utiliza Cage, dice Daniel Charles, ni siquiera son de Cage ${ }^{29}$. Dicha consideración se debe abordar de dos maneras:

27 Badiou 1998: 192.

28 Cage, 1973: 14.

29 Se ha optado por la palabra "acontecimientalidad" a fin de subrayar la condición activa del acontecimiento, a diferencia de "lo que acontece" o "lo acontecedero", palabras que remiten de alguna manera a una objetividad, a "algo" que tiene la característica de acontecer. De este modo se permanece ligado a la noción de évenementialité, utilizada frecuentemente por Alain Badiou o Jacques Derrida. 
1. Propiamente tal, es decir, como una pluralidad de acontecimientos (plurality of events) en un campo de posibilidades ${ }^{30}$ o condiciones. “¿Qué es una influencia divina?”, pregunta Henning Lohner. "Todo cuanto ocurre", responde John Cage ${ }^{31}$.

2. La "acontecimientalidad" en Cage no es una tautología con lo que efectiva u oficialmente ocurre. Al definir su método, escribe Cage:

$$
\begin{aligned}
& \text { My } \\
& \text { mEmory } \\
& \text { of whaT }
\end{aligned}
$$

Happened

is $\mathrm{nOt}$

what happeneD

(MÉTODO: Mi memoria de lo que ocurrió no es lo que ocurrió. John Cage, 1993, mesóstico inicial)

Lo que acontece no es lo que directamente acontece. Tal como en Badiou, existe aquí un pensamiento de aquello que el filósofo francés llama lo inexistente, a saber, "un elemento 'apareciente' que, relativamente a la indexación trascendental de este 'apareciente', no existe en el mundo" 32 . No obstante, reproduciendo la diferencia anterior, con Badiou el inexistente es introducido al mundo mediante un acontecimiento que lo incluye, de acuerdo con sus propias reglas o a su propio estilo. John Cage lo hace aparecer fugazmente, conservando fuertemente el poder de su inexistencia por medio de su inexistencia misma.

b) Para Alain Badiou el nombre propio del ser es el del vacío ${ }^{33}$. Dicho vacío es lógico y no ontológico ${ }^{34}$. El ser no supone ningún logos, ninguna lógica conectiva, ninguna harmonía. No obstante, está activo. Asimismo, los sonidos al aparecer, desprovistos de cualquier dispositivo relacional más que el que les otorga parcialmente el instante de un azar, no dejan de responder a su condición vibrante. He aquí que podemos quizás recobrar el comienzo que impulsó nuestra investigación. El sonido es, bien lo sabemos, vibración -actividad dice Cage-, y la música, al desnudo, despojada de sus empresas conectivas o comunicacionales, queda frente a aquello que podría ser reconocido como el comienzo de su propio ejercicio, esto es, el sonido vibrante del cual es, bien dice Cage, su continuación: "Music is continuity of sound" 35 . Podemos formularlo de la siguiente manera: se trata de un silencio lógico, no ontológico.

\section{LYOTARD}

En Discours, Figure, Lyotard ${ }^{36}$ afirma que lo que sostiene la actividad del arte es también aquello que el lenguaje no puede interiorizar. El lenguaje, como símbolo

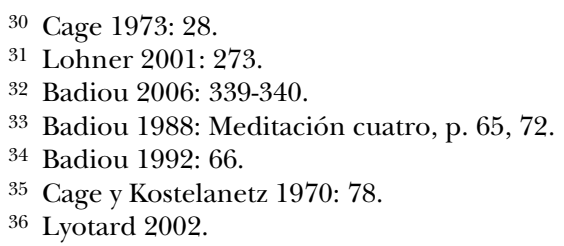


y distribución de símbolos reposa sobre un fondo insignificable que es la figura o lo figural.

"Aquello que es salvaje es el arte como silencio. La posición del arte es un desmentido a la posición del discurso. La posición del arte indica una función de la figura, que no es significada, y esta función (se encuentra) en torno y hasta el discurso. Indica que la trascendencia del símbolo es la figura, es decir una manifestación espacial que el espacio lingüístico no puede incorporar sin ser estremecido, una exterioridad que no puede interiorizar en significación. El arte es puesto en la alteridad en tanto que plasticidad y deseo, extensión curva, frente a la invariabilidad y a la razón, un espacio diacrítico. El arte quiere la figura, la 'belleza' es figural, no-ligada, rítmica”37.

Ese terreno es, insistimos, propio al arte, trabajo y constancia en la materia que "figuralmente" se proyectará a la construcción del símbolo. Y el asunto no demora: esta actividad figural "es acontecimiento" en tanto es el suceso primordial que sostiene al mundo significado $^{38}$. Todo lenguaje, se dirá, tiene su prehistoria figural, en donde el arte concibe su diseño y la estética de sus movimientos y en el que todo acontecimiento localizable, ciertamente, será una revolución del trazo, una revolución de la envoltura simbólica, una visión figural capaz de extenderse a posteriori como revolución de la significación establecida.

El paralelo está dado, y en tanto arte la música no sería ajena a esta concepción. No obstante, el estatus habría de ser diferente. La afirmación de Carmen Pardo y Daniel Charles citada anteriormente a propósito de Cage, a saber, que se trataría de algo diferente a lo visual, adquiere aquí toda su radicalidad. "Había hablado de acción musical directa (como si se tratase de orejas, no de ojos que se interponen)" 39 .

Pero ¿qué podríamos entender por "otra cosa que los ojos"?

Si lo propio del arte es la figura, considerar que a la música le corresponde también aquello es afirmar que a ella también le concierne la modelación y el cuestionamiento del futuro simbólico. Esto puede ser cierto en la medida en que se considera su condición habitual, la de ser un arte conectivo, en tanto la conectividad se relaciona con la imagen. Un ejemplo muy reciente de ello lo constituyen los Polytopes del músico franco-griego Iannis Xenakis. Siguiendo su compromiso con la formalidad de la composición y con la precisión conectiva de los devenires sonoros, Xenakis decide iluminar los sonidos y proyectarlos en el cielo, rememorando la máxima platónica sobre la Idea vista, al levantar la cabeza hacia el cielo para acceder a la Idea dibujada ${ }^{40}$.

En este sentido, el abandono por parte de John Cage de toda conectividad en música, es el abandono de la Idea y de todo rastro visual. Ya no es la figura, sino el sonido, ubicado no en una línea paralela, sino desplazándose en una profundidad similar, que puede despegar en una dirección diferente a la de toda una historia de la figurabilidad, de la simbolización, de la Idea. Esa tensión que John Cage instala en la sonoridad, se dirige al ejercicio de una escucha liberada de toda simbolización, de la recepción de sonidos dibujados o tallados. Se sitúa en una consideración que no deja de ser un misterio en tanto no se deja comprender por la producción visual y eidética. Por el contrario, descansa en su propio ejercicio, en su propio silencio, tratando secretamente, de manera "insabible", con una forma de pensar que al menos resiste a la fiscalización del pacto visual-simbólico.

37 Lyotard 2002: 13.

38 Lyotard 2002: 19-23.

39 Cage 1967: 4.

40 Platón, Fedro, 249b-c. 
"Encontré otra razón para escribir música que la lengua, la comunicación y todo eso"41, dice Cage. Esto es algo no menor si se considera que el sonido es llamado, con su música, a independizarse de la historia de la Idea. En este sentido, el sonido es acontecimiento "indiferenciado" de la figura: diferente pero sin su diferencia, como One. Esto significa simplemente que el sonido no queda sometido a las consideraciones de lo visual. Por el contrario, se resiste a ello para proyectar una historia del pensamiento que se engendraría con él, de manera radicalmente alternativa a una historia de la figura. Indiferentemente este pensamiento se posiciona por medio del misterio de la escucha y el silencio. Comienza por abandonar la idea de figurarnos y, con ello, la de representar y comprender. Otro pensamiento, como aquel que Derrida dijo una vez que le quitaba el sueño -la figura-.

Bajo una masiva producción que ha encaminado a la filosofía en las cuestiones de la imagen, o al costado de ella, como reflejo quizás de un privilegio inmediato que a la filosofía se le adjudicaría, una reflexión sobre el sonido puede encontrarse con formulaciones y conclusiones absolutamente diferentes. Estas descubren la propia singularidad del sonido y cuestionan los modos y los hábitos con los cuales se arma no solo el discurso filosófico o el discurso musical, sino también el quehacer reflexivo cotidiano.

\section{BIBLIOGRAFÍA}

Badiou, Alain

1988 L'être et l'événement. París: Seuil.

1989 Manifeste pour la Philosophie. París: Seuil.

1992 Conditions. París: Seuil.

1998 Cour traité d'ontologie transitoire. París: Seuil.

2006 Logiques des mondes. París: Seuil.

CAGE, JoHN

1967 A Year from Monday. Middletown, Connecticut: Wesleyan University Press.

1973 Silence. Middletown, Connecticut: Wesleyan University Press.

1993 Composition in Retrospect. Nueva York: Exact Changes.

2002 Je n'ai jamais écouté aucun son sans l'aimer: le seul problème avec les sons, c'est la musique. La Souterraine: La main courante.

Cage, John y Richard Kostelanetz

1970 Documentary Monographs in Modern Art. Paul Cummings (editor). Santa Barbara, California: Praeger.

Charles, Daniel

2002 Glosses sur John Cage. París: Desclée de Browser.

2011 John Cage, La tentation de l'Orient?”, publicado en formato PDF en su sitio web. http:/ / home.att.ne.jp/grape/charles/dc/dc_texts/dc-cage_tentation_de_1_orient.pdf P. 4.

DeRrida, Jacques

1967 De la Grammatologie. París: Les Editions de Minuit.

41 Meurice 1975. 
1976 "Fors", introducción, en Nicolás Abraham y María Torok. Cryptonomie. Le Verbier de l'homme aux loups. París: Aubier Flammarion, pp. 7-73.

1987 Ulysse gramophone. Deux mots pour Joyce. París: Editions Galilée.

1993 La voix et le phénomène. París: PUF.

1993 Spectres de Marx. París: Galilée.

2012 Espectros de Marx. El estado de la deuda, el trabajo del duelo y la Nueva Internacional. Traducción de Cristina Peretti y José Miguel Alarcón. Madrid: Trotta.

ECO, UMBERTO

1992 La obra abierta. Barcelona: Editorial Planeta De Agostini.

Kostelanetz, Richard (EDITOR)

2003 Conversing with Cage. Nueva York: Routledge.

LEIPP, ÉMILE

1971 Acoustique et musique. París: Masson.

Lewallen, Constance

2001 "Cage and the Structure of Chance", en David W. Bernstein y Christopher Hatch (editores). Writings through John Cage's Music, Poetry and Art. Chicago y Londres: The University of Chicago Press, pp. 234-243.

LOHNER, HENNING

2001 "The Making of Cage's One"11", en David W. Bernstein y Christopher Hatch (editores). Writings through John Cage's Music, Poetry and Art. Chicago y Londres: The University of Chicago Press, pp. 260-297.

Lussac, Olivier

2004 Happening et fluxus: polyexpressivité et pratique concrète des arts. París: L'Harmattan.

LYOTARD, J-F.

2002 Discours, Figure. París: Klincksieck.

Meurice, Jean-Michel

1975 Cage against Order. París: INA. Documental.

Pardo, CARMen

2006 "De la música como invitación a la nobleza. Entrevista con Daniel Charles", Zehar, No59. Gipuzkoa: Arteleku-ko aldizkaria (Centro de Arte Contemporáneo Vasco), pp. 59-63.

Pritchett, James

2001 "Cage and the Computer: a Panel Discussion", en David W. Bernstein y Christopher Hatch (editores). Writings through John Cage's Music, Poetry and Art. Chicago y Londres: The University of Chicago Press, pp. 190-209.

Sebestik, Miroslav,

1992 ECOUTE, Documental, JBA Production, SACEM, La Sept, Mikros Image. París: Centre Georges Pompidou.

STIEgLER, BERNARD

2005 De la misère 2. La catastrophè du sensible. París: Editions Galilée. 